Objetivo: avaliar as inter-relações recíprocas entre o transplante renal e a gravidez por meio da análise das intercorrências clínicas e obstétricas, bem como da investigação do desfecho perinatal. Métodos: foi analisada uma série retrospectiva de 39 casos de gestação em 37 portadoras de transplante renal no período de janeiro de 1997 a dezembro de 2003. As variáveis estudadas foram relativas ao transplante, às intercorrências clínicas e obstétricas e aos resultados perinatais. Um grupo controle composto por 66 grávidas sem patologias prévias, que freqüentavam pré-natal e deram à luz em 2002 e 2003 foi estabelecido para possíveis avaliações de significância estatística. Foram utilizados os testes de qui quadrado $\left(\chi^{2}\right)$ e exato de Fisher. Resultados: a média de idade das pacientes no momento da concepção foi de 27 anos. O doador vivo foi o mais freqüente. A ocorrência de disfunção do enxerto foi de $47,4 \%$, tendo sido a pré-eclampsia a sua principal causa. Perda do transplante ocorreu em 10,2\% dos casos. Entre os imunossupressores, a ciclosporina foi o mais utilizado. Hipertensão arterial crônica incidiu em $82 \%$ dos casos, anemia em $77 \%$ e infecção do trato urinário em $38,5 \%$. Quanto à via de parto, a cesariana foi realizada em $53,8 \%$, tendo como principal indicação a insuficiência placentária. A freqüência de préeclampsia foi de $28,2 \%$. Quanto às variáveis perinatais a prematuridade foi constatada em $46,1 \%$ dos casos, apresentando relação significativa com níveis de creatinina iguais ou superiores a $1,5 \mathrm{mg} / \mathrm{dL}$ no primeiro trimestre da gestação. Não houve relação com o uso de ciclosporina. Outra intercorrência observada foi restrição de crescimento fetal, verificada em $41,0 \%$ das gestações, não apresentando relação com os níveis iniciais de creatinina ou uso de ciclosporina. Conclusões: $\mathrm{O}$ grupo de estudo foi constituído por pacientes jovens. Disfunção do enxerto foi freqüente, havendo também casos de perda do transplante. Hipertensão arterial crônica, anemia e infecção do trato urinário foram as intercorrências clínicas mais freqüentes. Quanto à via de parto a cesariana teve incidência elevada. Pré-eclampsia ocorreu de forma significativamente maior que no grupo controle. Prematuridade e restrição de crescimento fetal foram as principais complicações perinatais.

PALAVRAS-CHAVE: Transplante renal; Imunossupressão; Pré-eclâmpsia

\title{
Estudo da prevalência dos fatores de risco do câncer de mama, numa população de funcionárias da Maternidade Escola Assis Chateaubriand da Universidade Federal do Ceará
}

Prevalence of risk factors for breast cancer study in a group of the female staff from the
school maternity hospital Assis Chateaubriand (Federal University of Ceará, Brazil)

Autor: Ércio Fereira Gomes

Orientador: Prof. Dr. Luiz Gonzaga Porto Pinheiro

Dissertação apresentada à Coordenação do Curso de Pós-Graduação em Tocoginecologia, da Universidade Federal do Ceará, como requisito parcial para obtenção do título de Mestre em Ginecologia e Obstetrícia, em 22 de dezembro de 2004

Para determinar a prevalência de alguns fatores de risco do câncer de mama, quantificar os fatores de risco de maior prevalência e delimitar grupos de maior risco, analisou-se uma população de 425 funcionárias da Maternidade Escola Assis Chateaubriand da Universidade Federal do Ceará, de vários níveis sociais e padrões raciais, mediante a aplicação de um formulário com o levantamento de 30 variáveis e realizou-se a mensuração do peso, altura, circunferência da cintura e do quadril. Calculou-se com estes dados a relação cintura/quadril, o índice de massa corpórea e o índice de Gail de todas as entrevistadas. Dos fatores de risco levantados, encontrou-se em 222 funcionárias $(52,2 \%)$ o índice de massa corpórea acima de 25 , a relação cintura/quadril maior do que 0,8 em 391 (92,1\%) e o sedentarismo em $314(73,1 \%)$ das entrevistadas. O grupo de maior risco encontrado e que merece seguimento diferenciado é formado pelos seguintes subgrupos: as $222(52,2 \%)$ funcionárias com o índice de massa corpórea maior ou igual a 25 , as $34(11,3 \%)$ que tiveram o primeiro filho após os trinta anos, as 34 $(11,3 \%)$ que fazem ou fizeram terapia de reposição hormonal, as $2(0,5 \%)$ portadoras de câncer de mama e as $15(20,8 \%)$ com parentes de primeiro grau acometidos de câncer de mama.

PALAVRAS-CHAVE: Neoplasias mamárias - fatores de risco. Neoplasias mamárias - grupos de risco. Câncer: rastreamento. 